\title{
As reações aos pós-modernismos
}

Coordenador do III Episted e do IV Colóquio de Epistemologia da Educação Física Editor do dossiê Epistemologia e teorias da Educação: as reações aos pós-modernismos Márcia Chaves-Gamboa

Coordenadora do III Episted e do IV Colóquio de Epistemologia da Educação Física Editora do dossiê Epistemologia e teorias da Educação: as reaçôes aos pós-modernismos

Régis Henrique dos Reis Silva

Editor do dossiê Epistemologia e teorias da Educação: as reações aos pós-modernismos

Revista Filosofia e Educação - Revista Digital do Grupo de
Estudos e Pesquisas Paideia - abre um importante
espaço para a publicação do dossiê intitulado Epistemologia e teorias da Educação: as reações aos pós-modernismos, que estampa as comunicações das mesas-redondas e os trabalhos apresentados no III Seminário de Epistemologia e Teorias da Educação (EPISTED) e no IV Colóquio de Epistemologia da Educação Física, ambos realizados na Faculdade de Educação da Unicamp nos dias 09, 10 e 11 de dezembro de 2008.

Os eventos denominados Seminários de Epistemologia e Teorias da Educação (EPISTEDs), organizados desde 2005 pelo Grupo de Pesquisas Paideia da Faculdade de Educação da Universidade Estadual de Campinas (Unicamp), objetivam divulgar, sistematizar, analisar e socializar a produção científica das áreas de Filosofia e Educação, assim como manter um permanente debate sobre a problemática da epistemologia e das teorias da educação, contando com a participação de outros grupos de pesquisa nacionais e estrangeiros. 
A partir do II EPISTED (2006), em vista do trabalho conjunto e das temáticas comuns com o Grupo Temático de Trabalho (GTT) de Epistemologia do Colégio Brasileiro de Ciências do Esporte (CBCE), propôs-se a realização dos seminários de forma integrada com os Colóquios de Epistemologia da Educação Física, que já vinham ocorrendo desde 2002.

Essa integração foi motivada pela constatação, nos registros da produção do Grupo Paideia, da significativa presença de pesquisadores oriundos da área de Educação Física, bem como pelos intercâmbios que vêm acontecendo com o CBCE e com os diversos grupos de pesquisa da Educação Física.

Por ocasião do III EPISTED e do IV Colóquio de Epistemologia da Educação Física, foram retomadas e aprofundadas as temáticas que se destacaram nos eventos anteriores, buscando-se uma linha de continuidade entre os eventos do Grupo Paideia e do GTT Epistemologia do CBCE. Os primeiros eventos giraram em torno dos problemas filosóficos da Educação e da Educação Física e abordaram o debate das tendências epistemológicas e pedagógicas das pesquisas recentemente desenvolvidas nesses campos do conhecimento. Particularmente, o debate sobre os "giros epistemológicos" e suas repercussões na pesquisa educacional ganhou momentos de maior aprofundamento, por ocasião do XV Congresso Brasileiro de Ciências do Esporte, realizado em Recife em setembro de 2007, retomando essas problemáticas e sugerindo a ampliação do debate, considerada a sua relação com as teorias do conhecimento e os desdobramentos na controvérsia epistemológica contemporânea entre modernidade e pós-modernidade. 
Atendendo a essa sugestão, o evento de 2008 se propôs a socializar resultados de estudos e pesquisas sobre a problemática da epistemologia e das teorias do conhecimento que sustentam a pesquisa em Educação e em Educação Física e a proporcionar um ambiente de interação entre pesquisadores interessados no debate contemporâneo das tendências epistemológicas e das teorias pedagógicas comuns às pesquisas das duas áreas. O referido evento foi organizado em torno da temática geral: Epistemologias e teorias do conhecimento na pesquisa em Educação e Educação Física: as reações aos pós-modernismos. Essa temática foi orientada pela seguinte ementa:

Compreender o debate sobre as novas correntes pós-modernistas que vêm influenciando a pesquisa em Educação e em Educação Física e que aborda os conflitos em torno da "virada linguística" e das suas reações, que se expressam nas viradas "hermenêutica", "pragmática" e "ontológica".

Tanto a defesa da "virada linguística" quanto as diversas reações foram ponderadas com base nas teorias do conhecimento e nas perspectivas histórico-sociais que se confrontam. Tais debates buscam oferecer subsídios aos pesquisadores para que se apropriem criticamente de novas ferramentas de análise e assim tenham melhor condição de superar os modismos, desvios e posturas ingênuas que diminuem a capacidade de compreensão das práticas pedagógicas e dispersam os compromissos históricos dos educadores.

A conferência principal, proferida por Celi Taffarel e apresentada em co-autoria com Joelma Albuquerque neste dossiê, sob o título Epistemologias e teorias do conhecimento em educação e educação física: reações aos pós-modernismos, defende a tese da relação entre as teorias 
do conhecimento e as perspectivas histórico-sociais, levando em conta que no embate de teorias também se confrontam diversos projetos históricos da sociedade.

A temática geral foi distribuída em três subtemas. No primeiro, Pósmodernidade e teorias críticas, são integrados trabalhos que discutem as reações aos pós-modernismos a partir das teorias críticas, cujos pressupostos e categorias são alvo do debate entre modernidade e pós-modernidade. Confrontam-se as teorias críticas com as póscríticas, argumentos e contra-argumentos que permeiam e afetam os fundamentos teóricos da pesquisa e das práticas pedagógicas em Educação e/ou em Educação Física.

O segundo subtema se refere à Produção científica em Educação e Educação Física e o atual debate teórico-metodológico. Com o surgimento de novas correntes denominadas genericamente de pós-modernas (pós-estruturalistas, neopragmatistas, pós-críticas), são rediscutidas as problemáticas dos modismos e dos limites teórico-metodológicos da pesquisa em Educação e em Educação Física. Essa problemática foi objeto de uma mesa-redonda, da qual foram extraídas, para o presente dossiê, três comunicações. Bernardete Gatti apresenta Reflexões sobre questões metodológicas e práticas em pesquisas em educação, tratando da identificação do campo relativo às pesquisas educacionais e suas relações com a formação do pesquisador e do educador. Silvio Sánchez Gamboa apresenta $O$ debate da pósmodernidade: as teorias do conhecimento em jogo e expõe a polêmica entre as atuais tendências de pesquisa, que incluem as pós-modernas que têm como base a "virada linguística" e representam também uma teoria do conhecimento. Nesse sentido, as teorias do 
conhecimento, incluindo nelas a "virada linguística", ajudam a esclarecer os limites e as implicações ideológicas das tendências e a revelar a necessidade da vigilância crítica, propiciando assim maior qualificação da pesquisa em educação. Paulo Evaldo Fensterseifer, na comunicação Educação Física: atividade epistemológica e objetivismo, apresenta o referencial hermenêutico como outro modo de legitimar os conhecimentos produzidos pela Educação Física.

O terceiro subtema foi dedicado às Teorias e práticas pedagógicas e as controvérsias epistemológicas contemporâneas. Nele abordaram-se as influências do debate contemporâneo entre modernidade e pósmodernidade nas teorias pedagógicas, os desdobramentos dessa controvérsia no campo da educação e suas interfaces com as políticas sociais e educativas. Essa problemática é desenvolvida na comunicação exposta por José Luis Sanfelice sob o título $A$ nova pedagogia da hegemonia no contexto da globalização, que elabora uma crítica às tendências pedagógicas neotecnicistas e neopragmáticas que se articulam com os interesses da globalização econômica mundial.

Outros 21 trabalhos que compõem este dossiê também desenvolvem a problemática geral proposta. São eles: Marxismo e cultura: contraponto às perspectivas pós-modernas, de David Romão Teixeira (UFRB) e Fernanda Braga Magalhães Dias (REE/Bahia); Pensamento pós-moderno e educação física: o marxismo como possibilidade, de Vilmar José Both (RME de Florianópolis/SC), Maristela da Silva Souza (UFSM) e Ecléa Vanessa Canei Baccin; A educação física e as teorias do conhecimento, de Ana Cláudia Saladini (UEL), Orlando Mendes Fogaça Júnior (UEL e Unopar) e Adrian Oscar Dongo Montoya 
(Unesp); Pressupostos teórico-metodológicos da genealogia: composições para um debate na educação, de Andréa Braga Moruzzi e Anete Abramowicz (ambas da UFSCar); Educação e pós-modernidade: um olhar wittgensteiniano, de Heloisa Helena Duval de Azevedo e Neiva Afonso Oliveira (ambas da UFPel); Ações do corpo humano, mente/cérebro e linguagem, de José Roque Aguirra Roncari (UEM); $O$ processo de (re)orientação teórico-epistemológica do departamento III FACED/UFBA (2004-2006), de Vamberto Ferreira Miranda (UNEB); Tendências epistemológicas da pesquisa em educação especial no Brasil: a análise das dissertações e teses do PPGEEs/UFSCar, de Régis Henrique dos Reis Silva (UFG e Unicamp); Vozes do silêncio: os sentidos do discurso delsobre sexualidade de mulheres paraplégicas, de Maria do Socorro Correia Lima; Ciência e capitalismo, de Júlia Paula Motta de Souza (Unicamp); Futebol, capitalismo e pós-modernidade: de consumo da arte a arte do consumo, de Marcelo Silva dos Santos (Faculdades Vértice e Sudamérica/MG) e Graziany Penna Dias (IFET/MG); Possibilidades da educação física na formação do trabalhador, de Jorge Oliveira dos Santos (IFRJ e RME de Duque de Caxias/RJ); Cognição e formação docente: bases epistemológicas para uma didática complexa, de Rita Ribeiro Voss (Universidade Braz Cubas); Educação crítica: uma possibilidade de formação "ambientalista" para professores de educação física, de Soraya Corrêa Domingues e Elenor Kunz (ambas da UFSC); O professor de educação física na escola: os saberes para o ensino, de Marilene Cesário (UEL) e Aline Reali (UFSCar); Epistemologia das concepções abertas no ensino da educação física: o legado de Jean Piaget, de Joaquim Francisco Lira Neto (REE/SP); A ciência da motricidade humana e as suas possibilidades metodológicas, de Ana Maria Pereira (UEL); Por um currículo multicultural, de Carlos Odilon da Costa e 
Rosana Soares (ambos da FURB); Educação sexual: contradições, limites e possibilidades, de Cláudia Ramos de Souza Bonfim (Faculdade Dom Bosco/PR); Epistemologia da ciência cognitiva e sua implicação ao ensino de ciências, de Elisângela Silva de Oliveira (UEAM), Evandro Ghedin (UEAM e UFAM) e Ethel Silva de Oliveira (Secretaria Municipal de Itacoatiara); Tendências investigativas no ensino de ciências na Amazônia, de Luís Carlos Lemos da Silva (UNINORTE) e Amarildo Menezes Gonzaga (UEAM).

Para finalizar, o professor Hermas Gonçalves Arana, em seu retorno ao grupo Paideia, escreve sobre A modéstia dos filósofos, brindando os leitores do presente dossiê, de uma forma tão pertinente quão oportuna, com uma reflexão que problematiza o magistério filosófico e destaca o papel do filósofo como observador crítico da produção do conhecimento.

Estamos certos de que os leitores têm em mãos um material de consulta e de pesquisa que contribui significativamente para ampliar o avanço dos conhecimentos sobre a Educação e a Educação Física no Brasil, justificando os esforços promovidos pelos organizadores dos EPISTEDs e dos Colóquios de Epistemologia da Educação Física no sentido de socializar os resultados dos trabalhos que vêm sendo realizados nas referidas áreas. 